\title{
Schema and Enhanced Teaching/Learning
}

\author{
Martha A. Astor ${ }^{1 *}$ \& Angelica M. Astor ${ }^{1}$ \\ ${ }^{1}$ Northern Arizona University, Flagstaff, Arizona, USA \\ *Martha A. Astor, E-mail: Angelica.Astor@nau.edu
}

Received: April 25, 2017

Accepted: May 5, 2017

Online Published: May 26, 2017

doi:10.22158/jecs.v1n2p141

URL: http://dx.doi.org/10.22158/jecs.v1n2p141

\begin{abstract}
Recent research advances offer new perspectives on teaching and learning. Minds are complex personality connected, emotion laden entities. The inclusion of schema could support these findings and provide insights into why we need to focus on differentiated instructional and teaching practices that empower students. The paper concludes with suggestions for retooling that will honor these newest findings about how we learn.
\end{abstract}

\section{Keywords}

Schema, learning theory, differentiated instruction, empowerment, DOK, emotional context

\section{Introduction}

\section{1 ... Still Emerging, How We Learn}

MSN News started an article on July 20, 2015 with this statement: "In a stunning discovery that overturns decades of textbook teaching, researchers have determined that the brain is directly connected to the immune system by vessels previously thought not to exist" (Note 1).

This amazing area, brain research, thinking, understanding is actively shifting. Our understanding of the human mind is evolving. Genome studies and imaging processes like PET and CAT scans provide visual evidence that children are born with minds that work in specific ways and have idiosyncratic strengths in learning that can be recognized, supported and developed (Laird et al., 2005). Research, particularly in infants and children (Bransford et al., 2000; Semrud-Clikeman, 2015) highlights progress in understanding the developmental and complex nature of learning and reasoning, and includes evidence that neonates are busy learning prior to birth.

Recent research on specific cellular excitation suggests that the mind makes its unique and individualized connections with meaning and meaningfulness. We know brain activity is quite different during recall and problem solving. The electrical and energy bursts in the brain confirm that there are many layers (Bloom) of knowing, internalizing, building personal connections, and then owning them enough to use them creatively and their occurrences do not mirror one another or even occur in the same quadrants of the brain most of the time. Further, one person's way of processing does not 
necessarily light up the same way. Yes, there are similarities. We are also finding complex differences in how individual minds work.

What does this mean for education? Specifically, each child is already on a different page when he or she starts school. Next, the learning process is individualized, so each child's learning can be enhanced in ways that are specific to that child. Likely, with such a distinct learning footprint, each young mind will need support in different ways, will have gaps and strengths not matched in the rest of the children. Learning to read, cipher, express the self in writing, not a "one size fits all" teaching process. Our classroom of children are not modular units, and any race is not to the top, but to get to know that child and how he or she is thinking to maximize the years of education.

Schema Piaget (1969) saw the footprints of this distinctive learning and a connection to emotions. He spoke of it as the processes of assimilation and accommodation in describing how children learned. This is tied to recognizing a very individualized process in learning, the building of schema. The schema is a small unit of meaning that may be key to better educational practice. It may also be a critical step in developing discrete, functional units of instruction that work for group and individual instruction. The notion of schema will be traced, defined, and explored in the context of advancing student ability to engage in critical thinking, and teachers' ability to streamline learning. In education, we continue to look for best practices. We also have a continued focus on brain research and how minds work (Bredo, 1994). We often use these findings to puzzle about the best way to induce learning and construct the educational environment.

Biological advances in brain work, MRI, CAT, and PET imaging processes are being connected to genome cataloguing. It is not providing strategic changes to education, in part because it is ongoing research. We have a host of authors positing theories and combining material about the way the mind combines the varied processes and insights and thus, we have advances in understanding metacognition. Most of the newer studies show connections and quirks in the way human minds may function. The research is still emerging of course, is not finished, and it is not yet definitive or even a completed model, but it changes what we know about learning, and the schema is a part of that progress and improving clarity about thinking (Fennimore \& Tinzmann, 1990; Markham, 2013.

Schema posits that the thinking and reasoning process is individualized. A schema is a collection of information that allows a student to make a personal connection with a construct, make meaning with it and personalize it as an element of learning or a base of operation for grounding or embellishment. It may have emotional cues or similar grounding. It may be organized and purposive, but it is at least as likely to be adventitious and include a set of ideas that do not typically belong together. It may have history, or it may be something that is constructed during the presentation of material.

The person with average intelligence can keep about 7 discrete pieces going to make meaning. No surprise that telephone numbers have traditionally been about 7 numbers. The student can take a set of 2 to 7 items and make a little model or construct an understanding. Most of the time it is an informal process. Good teachers inherently recognize and utilize these elements or units of meaning to get Published by SCHOLINK INC. 
subjects across, but may not delve into the student repertoire to analyze potential connecting points.

So a schema is brief, complex or simple, and made from small units of meaning. It is the way a particular brain organizes specific sets of information. It can have a personalized variety of connections, connotations and cognitive patterns. It can be a small discrete unit that does not acquire tracings to make it readily available for retrieval or it may be instantly highlighted due to emotional context. It may fit easily into existing patterns, thus fitting Piaget's notion of assimilation. Piaget $(1969,1972)$ defined schemata as the mental representation of an associated set of perceptions, ideas, and/or actions. He considered them to be the basic building blocks of thinking along with experiences, maturation and the need for balance or equilibration. So the idea of schema and schemata is grounded in developmental and cognitive theory (Rogoff, 1990).

One schema may exist in isolation or it may collide with another schema in such a way that the person feels compelled to keep both, so there is an accommodation, ala, Piaget, again. Or it may never tickle up against a contrasting or opposite structure, and the two may cohabit the person's memory system in direct contradiction to each other. This happens often and can lead to contradictory behaviors without cognitive overtones.

A metaphor can be shown in computer parlance. The host system may recognize a program that hooks with the Adobe programming or miss the hooks and cues and load up a program without transference between the two. The ability to organize and connect is critical to a working computer and most programs put all kinds of "connectors" or hooks on the programs to alert the new device about places where assimilation or accommodation will be successful and useful. But it does not always organize material or programs consistently or in useful ways for the user. In fact, at times it may create the potential for conflict and incompatibility that not only voids the programs but can actually disable the whole system.

This kind of side by side storing and "not connecting" happens frequently in our contrived lessons with students to induce learning and thinking. We recognize it in the student as a blank stare, the phasing out when the child needs a drink, fidgets, basically sits in direct instruction and "whirs" or stirs.

Let's use another example to make connections with this schema notion. Take the tinker toy. It consists of a kit of components. There are spools, dowels of different sizes and bits and pieces. These are the tools for constructing endless toys and models. Our minds do some of the same kinds of things when it comes to learning. We have an array of pieces and we put them together repeatedly to make meaning. The ability to do this is one of the ways we define intelligence. When playing with these bits and pieces, a child may make a series of unrelated trials and literally cover the floor with repeat tinkering Dunn and Larson (1998). Another person may look at some of the patterns that come with the pieces and try constructing complex pieces. Perhaps another time the person "tinkers" he or she will get drawn to a set of repetitive patterns or make a complex pattern that is validating or definitive and different from other things tried before. The novelty, alone, may add enough emotional context to set up tracing and retrieval. There are also individuals who do not "connect" with the pieces, oblivious to possibilities and 
frustrated if forced to work with the "toy".

Learning happens in the same way. The collection of tinker toys elicits some pretty standard responses from first time and repeats users. There are some youngsters who are never drawn to the material, some who quickly lose interest, those who enjoy the challenge, time themselves, compete to make new diagrams and construct new ideas. There are youngsters who completely miss the point and never put the pieces together. Instead they use the parts in disparate projects and unusual ways. If someone comes along and models a ways to put the pieces together, the student may try it, but there are many who won't find the toy amusing or intriguing. Some may not be able to figure out how to use it at all.

Presented with material, some children immediately construct a schema and others are oblivious. So this is another component of the schema. "Teaching" a schema does not make it useful, meaningful or even "stick". Because minds work differently, and it is the work in the mind that builds the schema, teaching does not equal learning. The schema helps us recognize this connective way of making sense of input and utilizing the complex array of thoughts, tools and connections that are part of how children learn. Recognizing and enhancing the process speeds learning, organizing and retaining. It also provides a sign post to the recurring failures we have inducing learning in a significant number of students in any given room at every given point in the lessons.

What is it about the schema that might help educators understand the success and failure of learning? A schema has both cognitive and emotional content. Schemas can develop without a person recognizing that it is occurring, and thus, the "hooks" or connectors may not respond to logical recall tactics. A schema is one of the ways that brains construct and organize material and collect information, usually without notifying the conscious processes that it is occurring in the background. Work with young children suggested that $70 \%$ of the things a child learned during the day were not connected to anything that others or the child intentionally set up. Further the majority of these unsolicited collecting pieces were seldom reviewed for organization, correctness or were later, even retrievable.

\section{Many Ways to Make Meaning}

We have a number of learning theorists who describe the value of recognizing top-down and bottom-up as ways of learning. In research we also refer to these very different ways of thinking and reasoning as deductive and inductive. None of the dichotomies are synonymous, but they denote recognition that minds can learn and reason in quite different ways. These bifurcations in thinking may also be tied to global and linear ways of thinking or making meaning and include some of the contextual processes described as learning styles and multiple intelligences.

This notion, that we make meaning in a number of ways, that minds make sense out of input using varied frameworks, aligns with constructivism. This is a philosophical position that views knowing as an outcome of personal experiences and the knowledge gained from others (Dewey, 1933, 1998). Our reality, experiences, ways of thinking and being are mediated by prior-constructed realities that we take for granted in ourselves and in others, or may not even recognize as being in place. This can also be 
gleaned from the Piagetian idea that human cognitive development is a collecting and adapting process (Piaget \& Inhelder, 1969; Flavell, 1996). His connection to schema consists of the processes termed assimilation, accommodation and correction.

Some of us build the schema with bits and pieces. This is a linear format. Students who learn to read using a phonetic approach tend to have more linear minds. The bits and pieces get collected, the schema is constructed as the lessons go along, and thus phonemic patterns, awareness and literacy are built. Like a 500 piece puzzle, each piece finds a home and the picture emerges.

Some minds build a more global awareness. With this kind of thinking, phonics lessons may be constructed, built, memorized and replicated, but failing the "big picture" notion, the student lays the pieces around, disconnected and unrecognized as building blocks for reading. The student can reproduce the lesson, make the appropriate sounds, but reading isn't the final result. Instead, the mind may have categorized the pieces by color, so instead of a finished sentence, there are piles of odd red unknown words, green ones with double letters, purple ones that all look different but sound the same, etc. The student, family and educator are stymied, because the appropriate efforts have been made, but reading has not happened.

Another piece to understanding the schema is emergence of thoughts or ideas cobbled together based on an emotion. Anyone who has seen the movie, Psycho, understands why there are shower curtains all across the world that have a clear plastic cut-out at eye level. Twenty years of showering without incident don't disconnect that sense of unrest when we get into the hotel shower. Receiving a ticket with angst or unalleviated frustration is likely to lead to a smirk when a policeman is referred to as "Officer Friendly". Twenty-two positive experiences do not reframe or refile that schema.

\section{Affective Filters and Emotion in Learning and Teaching}

The schema building process, automatic or purposive comes with an affective filtering system. We know that emotion laden material can get the most lost... i.e., unconscious or irretrievable content that is rather like a shadow. We act upon the beliefs without recognizing the belief system itself. Dad smoked whenever there were fusses in the family. From nowhere, a person gets the urge to light up after being confronted with bad news. A person is repeatedly invited to holiday events by friends but never seems to be able to show up on the appointed day.

How does this connect to school? Every morning about 9:30, a youngster feels sick and asks to go to the nurse. There is no apparent reason, but the teacher eventually tumbles across the old schedule and realizes she used to have math at 9:40. Reading is at 10:30. A youngster throws toys at his neighbor and gets sent to the principal's office. The Aide in the room notes that this happens every morning with this youngster and shakes his head. He sees it as the student avoiding the unavoidable... Reading. Better to be in trouble than to confront the dragon of misery and jumbled letters.

Emotional or internal energy may account for part of the reason schema building can be effortless. When a student perceives a need for information, there is an energy and drive or motivation that gives a 
boost to learning ideas, constructing the schema, locating and selecting connectors or "hooks" to other ideas. This suggests that developmental press, or critical periods may exert pressure and excite energy and arousal around tasks to give them atypical urgency. It may also be that it most closely matches the informal learning and processing that occurred in the early years. It may include control and will as part of the boost or barriers. Understanding how this works with youth is not clear, but circumstances and responses suggest it is a productive inquiry. Until it is understood, it is notable and important in our induction of ideas and information. It may also be a hot spot in our efforts to support critical thinking.

The recognition and use of the emotional portion of schema building can be used to enhance teaching. Sales people regularly use it and it is one of the ways students and teachers get access to the emotional context. Locating the context for adding content can be utilized to enhance rate and retention of ideas in teaching. The savvy teacher works at this with the lesson "preset".

One of the lessons we learned from constructivism is that the development of learner knowledge, attitudes and beliefs are idiosyncratic and to some extent unpredictable as a result of the complex personal processes of learning (Glasersfeld, 1995; Kafai \& Resnick, 1996). There is a consensus that the mechanical processes of transmission of knowledge or image of subjects like reading and mathematics to learners is not generally effective (NCTM, 1989). There are theories, too, that suggest schemas tend to be social as well as individual. Social constructivists like Ernest (1999). Crotty (1998), Gredler (1997), Prawat and Floden (1994) and posit that knowledge is, in part, a human product, and is socially and culturally constructed.

These ideas emphasize culture and context in understanding how we construct knowledge (Derry, 1999; McMahon, 1997). This is associated with the developmental theories of Vygotsky (1978), Bruner (1990), and Bandura's (1986) social cognitive theory (Schunk, 2000). From such theories, it is possible to surmise that a stereotype is a form of schema. It may be embedded from childhood, part of a media campaign, hapless exposure, carefully orchestrated or the result of a series of personal experiences. Individuals create meaning through their interactions with each other and with the environment and cultural milieu in which they live.

Students do the same with knowledge construction. The student brings a personalized, idiosyncratic sense to the material presented. It is as though a transaction ensues if the student chooses to consider the material. The material is acted upon by that student, and the student attitude, intentions and schemata brought to bear, meld to achieve a personalized outcome or understanding. This clarifies the level of individuation attached to comprehension that leads to deeper levels of understanding and the importance of valuing individualized outcomes in reading. It points to constraints in grading that are not commonly addressed but could have connotative impact with respect to student interest in striving to develop personalized outcomes in reading and writing.

A cogent offshoot from recognizing the emotional context of schema building is the manner in which we continue to maintain an established belief system. The strength and permeability vary. Once a strong set of beliefs is in place it can act as an affective filter, sifting through information and 
essentially determining which will be considered and which will not pass through to be included as part of intentional consideration.

Most of us learn one mistake at a time, literally. If we are free to act out our energy surrounding things that make us curious, we build energy and enthusiasm for trial and error. Mistakes do not cost us, they energize us. If we are shamed, our excitement is blocked or we receive blame or lost points, lost privileges, lost "face" in our efforts, we stop risking, stop trusting, sometimes even feel a sadness about being at school. We have few choices about the adult "in charge" and the curriculum in the current system. It may be important to make efforts to blend the right adults and children together for this life building work.

\section{Formative Assessment and Probes are Vital}

Based on the recognition that students already have schematic "tissue" or building blocks sitting around, it is critical to have a formative assessment process as part of any learning situation. The student and the teacher need to be able to develop and utilize a series of checks to determine likely acceptance of the information that is being "taught and learned". As a student is introduced to ideas, it is almost as though an induction process needs to take place, assessing presence of prior schemas, emotional content or blocks and affective filters and their strength (Alesandrini \& Larson, 2002; Matthewson, 2004). The format for determining student pre-sets could be used with youngsters as the introduction of a unit. They need not be formalized, but it is important to get a general sense of the way an educator could add information to student individual responses to concepts. Explicitly, one can do a pre-set for the class in general, but for students who do not appear to be connecting to the lesson, individualized detecting will need to take place.

Math was intentionally chosen for this example because many youngsters establish an emotional "knee jerk" to specific content. Negative numbers is one example. Addition and subtraction are often taught to students providing a schema that becomes an unintentional block to negative numbers. We line numbers up in subtraction and explain to second and third graders that larger numbers may not be subtracted from smaller numbers. That lodges, cognitively and is built upon as schema, and when higher math requires the more complex notion of negative numbers, some students will not entertain the construct.

27

$\underline{-13}$

14 YES! Correct
42

$\underline{-77}$

NO way! Can't do this!

To begin the positive building of negative numbers, the teacher teases out student responses to the idea of taking a large negative number from a smaller positive number as well as looking for experiences that may have interfered in previous lessons on debit and credit. It may also be useful to do a pretest on the concept using red and black licorice to do hands on examples.

This kind of teaching process can be established as a teaching schema, $\mathrm{n}$ individual response set in 
watching for the student who seems unable to approach material. It is likely to become a habit of mind that is productive, if blocks are seen as something that can be teased out and addressed instead of becoming the unintentional stop sign. It is a better practice than the age old refrain from the teacher when a student says, "I can't do that". It is a bit arrogant to ignore the student message and helpfully respond, "Of course you can".

\section{Teaching and Learning is Idiosyncratic}

Learning about schemata and recognizing them as building blocks for learning, reasoning and problem solving provides an opening for teachers to view the teaching process differently. Teaching is much more idiosyncratic than previous learning theories suggest. Applied to much of our current practice, there are multitudinous alterations we can make that are likely to enhance student motivation, retention and escalate the move from knowledge based acquisition of facts to genuine pleasure at the opportunity to feel personally engaged in ideas and rewarded for creative, escalated excitement about ideas.

Many of us cannot build a schema from another person's abstractions. Bartlett (1932) noted that explicit information in a text was insufficient for the specification of the meaning of that text. Instead, the complete meaning came from combining personal information from the reader's various sources as a response to the material, thus comprising the context of the text, so prior knowledge task context, emotional context and previous schemata aroused by the material combine to produce a text's understood meaning that is referred to as construction.

This makes reading beyond decoding just as messy as teachers tend to find it. Comprehension work is a problem solving exercise, ongoing from an initial sentence and idea to the ensuing sentences, paragraphs and explicated ideas. It is not enough to teach story vocabulary, and in fact, teaching vocabulary is an example of the complexity. Part of vocabulary work is locating and developing overarching schemata that will work with the story and provide the internal cues so students are open to, recognize and then understand the inferences in the material. Part of vocabulary work is finding the connectors to existing schemata so the student mind works to build the connections and then maintains the material long enough to do the reading from that framework. Clearly the strength of the schema, memory and processing speed support or impede this process.

Organizational constraints come into play with comprehension work. Shapiro and Tirre (1980) noted two questions that are still unresolved. The first is the question of individual differences. It appears that students with reading difficulties have individual approaches to understanding the text that are not held in common by others who are having instructional difficulties. Instead, solutions that may work for these youth need to be differentiated to address the specific way the student is reading and efforts to resolve the concerns require specific problem solving, based on the approach an individual struggling learner is using. Thus class instruction and small group induction tend to fail. The work of finding the solution is a two-person journey, including an insightful, committed sleuth of a teacher and a willing student. 
The pilot study looking at schema and reading by Spiro et al. (1979), Rummelhart (1980) found that three of these etiological factors (decoding skill, cognitive style, and general schema availability) supported understanding the processing style in reading for fifth- and sixth-grade children. This underscores and gives additional support to recognizing that individualized vocabulary concerns are just the initial point of differentiating instruction for learners who are struggling.

Two main types of schemata exist for reading: content schema, representing existing knowledge of objects and events; and textual schema, including knowledge of discourse structure and conventions (Clark, 1990), with at least six major schema functions important to reading comprehension: (1) schemata provide slots for assimilating additional knowledge; (2) schemata aid in judging what is important; (3) schemata aid in making inferences; (4) schemata help summarize and edit material; (5) schemata activated during reading facilitate an orderly memory search for relevant information; and (6) schemata function in inferential reconstruction, including how the size of schemata affect learning remembering versus learning. Schema building can be taught and practiced. The schema process may not automatically generalize to other subjects, but can be cued and utilized. Schema theory can help explain failure to comprehend: there may not be enough clues to activate existing schemata, the reader may not have appropriate schemata, and failure to comprehend may result when the reader makes an interpretation but not the one intended.

This snapshot of some of the research in reading induction and schema opens a very different look at learning. There is fresh thinking to do about how students learn and how we may choose to structure and effect teaching. Schema may be one of the puzzle pieces that act as a springboard to combining new information with current useful practices. There is room for creativity here. No model on any level is yet considered to be a fully valid description of brain function (Markham, 2013).

\subsection{Proposed Retooling (Affeld \& Astor, 2015)}

The inclusion of schema and understanding its function in learning is one of the changes needed in education. Minds are complex, personality connected entities. They are honestly unique in spite of global similarities. Our approach to teaching and learning currently depends on $80 \%-90 \%$ focus of all students in the classroom on the same concept, but we can support and honor the idea that learning is unique. We can empower forward thrust and impetus, individual thought and individual insights and needs.

In summary, these insights support:

a. Utilizing bottom up and top down approaches in our teaching, tailored to the learning strengths of individual students.

b. Recognizing the emotional lability in preparing students to learn and connecting to the affective components content evokes as students are constructing schema.

c. Seeking out and honoring the developmental press that is part of the energy of embracing or shunning academic tasks and component.

d. Operating from a "success" model; finding and building on student strengths and capacity, and 
setting individual curriculum that matches student learning and thinking styles and supports the student's perception of what is working and what is not.

e. Addressing layers of development, not just attention to physical and cognitive areas (PEPSI). http://www.jan.ucc.nau.edu/ jde7/ese425/bio/online_read_1.html

f. Trusting children and what they tell us about learning and about their needs. Children are not lazy at learning. They worked tirelessly before they came to school. They are born already learning. They want and need to learn. So if the impetus and "fire" of learning is missing, there is work to be done to rekindle it (Competition, grading on the curve, shaming and bullying do not rekindle that fire).

\section{Natural Proclivities Likely to Support Enhancements}

1. Youth have internalized pressures and developmental press to learn, think, and actualize.

2. Human beings are self-willed, and given the support, skill sets and direction, will push themselves to learn, think, and act in empowered ways.

3. Human love of succeeding makes it likely that students will be willing to maintain records, achievements and support of learning and take progress seriously if it is within the scope of what is possible for them and not consistently at the frustration level.

4. Most teachers actually like children very much. If we sharpen their skills and help them learn to work effectively in a variety of ways that support the child as learner, there will be a change in perceived satisfaction from teachers, who want to be valued, loved and see children as successful.

\section{References}

Alesandrini, K., \& Larson, L. (2002, January/February). Teachers bridge to constructivism. The Clearing House, 75(3), 118-121. https://doi.org/10.1080/00098650209599249

Astor, Angelica M., \& Affeld, Martha A. (2015). Education: Retooling for Tomorrow. LAP LAMBERT Lap-Lambert Academic Publishing OmniScriptum GmbH \& Co. KG. Heinrich-Böcking-Str. Saarbrücken, Germany.

Bandura, A. (1986). Social foundations of thought and action: A social cognitive theory. Englewood Clifts, NJ: Prentce-Hall.

Bransford, J. D., Brown, A. L., \& Cocking, R. R. (2000). How People Learn: Brain, Mind, Experience, and School: Expanded Edition. Washington, D. C.: National Academy Press.

Bredo, E. (1994). Reconstructing educational psychology: Situated cognition and Deweyian pragmatism. Educational Psychologist, 29(1), 23-25. https://doi.org/10.1207/s15326985ep2901_3

Bruner, J. (1990). Acts of meaning. Cambridge, MA: Harvard University Press.

Clark, R. (1990). Schema theory and reading comprehension.

Crotty, M. (1998). The foundations of social research: Meaning and perspective in the research process. London: Sage Publications. 
Derry, S. J. (1999). A Fish called peer learning: Searching for common themes (A. M. O’Donnell, \& A. King, Eds.).

Dewey, J. (1933/1998). How we think. Boston, MA: Houghton Mifflin Company.

Dunn, S., \& Larson, R. (1998). Design technology: Children's engineering. Bristol, PA: Taylor and Francis Publishers (The Falmer Press).

Ernest, P. (1995). Values, Gender and Images of Mathematics: A Philosophical Perspective. International Journal for Mathematical Education in Science and Technology, 26(3), 449-462. https://doi.org/10.1080/0020739950260313

Ernest, P. (1999, March 23). Social Constructivism as a Philosophy of Mathematics: Radical Constructivism.

Fennimore, T., \& Tinzmann, M. (1990). What is a thinking curriculum? Oak Brook, IL: North Central Regional Educational Laboratory. Retrieved December, 2002, from http://www.asa3.org/ASA/education/think/thinking-ft.pdf

Flavell, J. (1996). Piaget's legacy. Psychological Science, 7(4), 200-203. https://doi.org/10.1111/j.1467-9280.1996.tb00359.x

Glasersfeld, E. von. (1995). Radical Constructivism: A Way of Knowing and Learning. London: Falmer Press.

Gredler, M. E. (1997). Learning and instruction: Theory into practice (3rd ed.). Upper Saddle River, NJ: Prentice-Hall.

Kafai, Y., \& Resnick, M. (1996). Constructionism in practice: Designing, thinking, and learning in a digital world. Mahwah, NJ: Lawrence Erlbaum Associates.

Laird, A. R., Lancaster, J. L., \& Fox, P. T. (2005). BrainMap: The social evolution of a functional neuroimaging database (PDF). Neuroinformatics, 3(1), 65-78. https://doi.org/10.1385/NI:3:1:065

Markham, H. (2013). Seven challenges for neuroscience. Functional neurology, 28(3), 145-151.

Matthewson. (2004). Schema Theory. Retrieved June 26, 2015, from http://www.csus.edu/indiv/g/gipej/teaparty.pdf

McMahon, M. (1997, December). Social Constructivism and the World Wide Web-A Paradigm for Learning. Paper presented at the ASCILITE conference. Perth, Australia.

NCTM. (1989). Curriculum and Evaluation Standards for School Mathematics. Reston, Virginia: National Council of Teachers of Mathematics.

Piaget, J. (1972). The psychology of the child. New York: Basic Books.

Piaget, J., \& Inhelder, B. (1969). The psychology of the child. New York: Basic Books.

Prawat, R. S., \& Floden, R. E. (1994). Philosophical Perspectives on Constructivist Views of Learning. Educational Psychologist, 29(1), 37-48. https://doi.org/10.1207/s15326985ep2901_4

Rogoff, B. (1990). Apprenticeship in thinking: Cognitive development in social context. New York, NY: Oxford University Press. 
Rumelhart, D. E. (1980). Schemata: The building blocks of cognition. In R. J. Spiro et al. (Eds.), Theoretical Issues in Reading Comprehension. Hillsdale, NJ: Lawrence Erlbaum.

Schunk, D. H. (2000). Coming to terms with motivation constructs. Contemporary Educational Psychology, 25, 116-119. https://doi.org/10.1006/ceps.1999.1018

Semrud-Clieman, M. (2015). Research in brain function and learning: The importance of matching instruction to a child's maturity level.

Vygotsky, L. (1978). Mind in society. Cambridge, MA: Harvard University Press.

\section{Note}

Note 1. http://www.psychiatrictimes.com/schizophrenia/stunning-discovery?GUID=6C805A30-52A34DD9-9C64-737E2508E025\&rememberme=1\&ts=21072015\#sthash.fkqOSHVS.dpuf 